\title{
Surgical ablation of atrial fibrillation with bipolar radiofrequency as the primary modality
}

\author{
A. Marc Gillinov, MD, ${ }^{a}$ Patrick M. McCarthy, MD, ${ }^{a}$ Eugene H. Blackstone, MD, ${ }^{a}$ Jeevanantham Rajeswaran, MSc, ${ }^{b}$ \\ Gosta Pettersson, MD, PhD, ${ }^{a}$ Joseph F. Sabik III, MD, ${ }^{a}$ Lars G. Svensson, MD, PhD, ${ }^{a}$ Delos M. Cosgrove, MD, ${ }^{a}$ \\ Kathleen M. Hill, RN, ${ }^{a}$ Gonzalo V. Gonzalez-Stawinski, MD, ${ }^{a}$ Nassir Marrouche, MD, ${ }^{\mathrm{c}}$ and Andrea Natale, $\mathrm{MD}^{\mathrm{c}}$
}

Electronic appendixes are available online. $\beta$

Objectives: In studying cardiac surgical patients undergoing atrial fibrillation ablation with bipolar radiofrequency, we sought to (1) quantify the time-related prevalence of atrial fibrillation postoperatively and identify its risk factors and (2) determine time-related ablation failure and its risk factors.

Methods: From November 2001 to January 2004, 513 patients underwent atrial fibrillation ablation (bipolar radiofrequency alone or with cryothermy) and other cardiac operations. Rhythm documented on 3495 postoperative electrocardiograms was used to estimate the prevalence of and risk factors for atrial fibrillation across time. Ablation failure was defined as occurrence of atrial fibrillation any time beyond 6 months after operation.

Results: Prevalence of postoperative atrial fibrillation peaked at about 1 month, decreased to $13 \%$ at 6 months, and gradually increased thereafter. Risk factors associated with increased prevalence varied by time period and included older age $(P=.004)$ for early occurrence, lesion set in permanent atrial fibrillation $(P=.02)$ for late occurrence, and larger left atrial diameter $(P=.02)$ and permanent atrial fibrillation $(P<.0001)$ for occurrence across the entire time span. Freedom from ablation failure was $72 \%$ at 12 months. Risk factors for ablation failure included lesion set in permanent atrial fibrillation $(P=.001)$, longer duration of atrial fibrillation $(P=.01)$, and larger left atrial diameter $(P=.03)$.

Conclusions: Bipolar radiofrequency enables extension of ablation to most cardiac surgical patients with atrial fibrillation. Recurrence is influenced by the type and duration of atrial fibrillation, choice of lesion set in permanent atrial fibrillation, and left atrial size. Early operation, careful choice of lesion set, and left atrial reduction might enhance results.

From the Center for Atrial Fibrillation an the Department of Thoracic and Cardiovascular Surgery, ${ }^{a}$ the Department of Qualitative Health Sciences, ${ }^{\mathrm{b}}$ and the Department of Cardiovascular Medicine, ${ }^{\mathrm{c}}$ The Cleveland Clinic Foundation, Cleveland, Ohio.

Drs McCarthy and Gillinov are consultants to Atricure, Inc, West Chester, Ohio.

Read at the Thirtieth Annual Meeting of The Western Thoracic Surgical Association, Maui, Hawaii, June 23-26, 2004.

Received for publication June 23, 2004; revisions received Oct 21, 2004; accepted for publication Dec 15, 2004.

Address for reprints: A. Marc Gillinov, MD, Department of Thoracic and Cardiovascular Surgery, The Cleveland Clinic Foundation/ F24, 9500 Euclid Ave, Cleveland, OH 44195 (E-mail: gillinom@ccf.org).

J Thorac Cardiovasc Surg 2005;129:1322-9

$0022-5223 / \$ 30.00$

Copyright (c) 2005 by The American Association for Thoracic Surgery

doi:10.1016/j.jtcvs.2004.12.010

A trial fibrillation $(\mathrm{AF})$ is common in patients presenting for cardiac surgery and, if left untreated, is associated with reduced survival and increased risk of stroke. Successful intraoperative ablation of AF improves outcomes, ${ }^{1-3}$ but until recently, surgeons were unlikely to combine ablation and other cardiac operations. This is because although the Cox maze III procedure eliminates AF in $70 \%$ to $90 \%$ of patients, it is complex and increases operative time..$^{3-5}$

Recently, there has been great interest in direct surgical ablation of AF, fueled by technologic advances and demonstration that the pulmonary veins and left atrium are the primary sites of drivers of AF..$^{6-12}$ Ablation technologies, such as bipolar radiofrequency (RF), enable surgeons to isolate the pulmonary veins and create linear left atrial lesions rapidly and safely. ${ }^{6-11}$ However, results of these new procedures require scrutiny. The objectives of this study of cardiac surgical patients undergoing $\mathrm{AF}$ ablation with bipolar RF were to (1) quantify the time-related prevalence of AF after operation and identify its risk factors and (2) determine time-related ablation failure and its risk factors. 
TABLE 1. Patient characteristics

\begin{tabular}{|c|c|c|c|}
\hline Characteristic & $\mathrm{n}^{*}$ & No. & $\%$ \\
\hline Demographic & 513 & & \\
\hline Male & & 298 & 58 \\
\hline Age $(y)$, mean $\pm S D$ & & $67 \pm 12$ & \\
\hline \multicolumn{4}{|l|}{ Cardiac } \\
\hline NYHA functional class & 513 & & \\
\hline I & & 93 & 18 \\
\hline II & & 293 & 57 \\
\hline III & & 111 & 22 \\
\hline IV & & 16 & 3.1 \\
\hline Emergency operation & 513 & 4 & 0.78 \\
\hline Left main diseaset & 493 & 34 & 6.9 \\
\hline LAD disease $\dagger$ & 493 & 165 & 33 \\
\hline Circumflex disease $†$ & 493 & 133 & 27 \\
\hline Right coronary disease ${ }^{\prime}$ & 489 & 144 & 29 \\
\hline Previous cardiac operation & 513 & & \\
\hline 0 & & 426 & 83 \\
\hline 1 & & 76 & 15 \\
\hline 2 & & 10 & 2.0 \\
\hline 3 & & 1 & 0.19 \\
\hline History of myocardial infarction & 513 & 141 & 27 \\
\hline Mitral valve disease cause & 513 & 354 & 69 \\
\hline Degenerative $\ddagger$ & & 211 & 60 \\
\hline Rheumatic $\ddagger$ & & 76 & 21 \\
\hline Ischemic $\ddagger$ & & 36 & 10 \\
\hline Endocarditis $\ddagger$ & & 2 & 0.56 \\
\hline Functionalf & & 16 & 4.5 \\
\hline Radiation $\ddagger$ & & 2 & 0.6 \\
\hline Prosthetic valve dysfunction $\ddagger$ & & 10 & 2.8 \\
\hline Unspecified $\ddagger$ & & 1 & 0.3 \\
\hline Mitral regurgitation grade & 512 & & \\
\hline 0 & & 67 & 13 \\
\hline $1+$ & & 70 & 14 \\
\hline $2+$ & & 67 & 13 \\
\hline $3+$ & & 108 & 21 \\
\hline $4+$ & & 200 & 39 \\
\hline Atrial fibrillation type & 513 & & \\
\hline Permanent & & 289 & 56 \\
\hline Persistent & & 74 & 14 \\
\hline Paroxysmal & & 139 & 27 \\
\hline Flutter & & 11 & 2.1 \\
\hline Duration of atrial fibrillation (mo) & 512 & $3,24,108 \S$ & \\
\hline LV end-diastolic diameter $(\mathrm{cm})$ & 444 & $5.1 \pm 0.98$ & \\
\hline LV end-systolic diameter $(\mathrm{cm})$ & 442 & $3.5 \pm 1.1$ & \\
\hline LA diameter $(\mathrm{cm})$ & 427 & $5.12 \pm 0.90$ & \\
\hline Fractional shortening & 442 & $0.32 \pm 0.12$ & \\
\hline Ejection fraction (\%) & 442 & $58 \pm 18$ & \\
\hline Estimated wall stress & 442 & $0.49 \pm 0.17$ & \\
\hline \multicolumn{4}{|l|}{ Noncardiac } \\
\hline Hypertension & 510 & 327 & 64 \\
\hline $\mathrm{BUN}\left(\mathrm{mg} \cdot \mathrm{dL}^{-1}\right)$ & 508 & $22 \pm 11$ & \\
\hline Bilirubin $\left(\mathrm{mg} \cdot \mathrm{dL}^{-1}\right)$ & 480 & $0.5,0.8,1.4 \S$ & \\
\hline Hematocrit $(\%)$ & 501 & $38 \pm 5$ & \\
\hline
\end{tabular}

TABLE 1. continued

\begin{tabular}{lccc}
\hline Characteristic & $\mathbf{n}^{*}$ & No. & $\%$ \\
\hline Preoperative thrombolic events & 513 & & \\
$\quad$ Syncope & & 49 & 9.6 \\
Transient ischemic attack & & 49 & 9.6 \\
CVA & & 48 & 9.4 \\
$\quad$ Embolus & 9 & 1.8 \\
Intraoperative support & & \\
$\quad$ Aortic clamp time (min) & 504 & $87 \pm 32$ & \\
CPB time (min) & 512 & $113 \pm 39$ & \\
Procedure & 513 & & \\
Mitral valve repair & & 227 & 44 \\
Mitral valve replacement & & 127 & 25 \\
Aortic valve replacement & & 164 & 32 \\
Tricuspid valve repair & & 133 & 26 \\
CABG & & 195 & 38 \\
\hline
\end{tabular}

$N Y H A$, New York Heart Association; $L A D$, left anterior descending coronary artery; $L V$, left ventricle; $L A$, left atrium; $B U N$, blood urea nitrogen; $C V A$, cerebrovascular accident; $C P B$, cardiopulmonary bypass; $C A B G$, coronary artery bypass grafting. *Data available. $\dagger>50 \%$. $\ddagger$ Percent of patients undergoing mitral valve surgery. §15th, 50th (median), and 85th percentiles.

\section{Materials and Methods \\ Patients}

From November 2001 to January 2004, 513 patients underwent AF ablation with bipolar RF at The Cleveland Clinic Foundation. This represents $25 \%$ of the 2079 patients with preoperative AF undergoing cardiac surgery during this time frame and $67 \%$ of the 769 patients who had some form of AF ablation. Patients were identified, and preoperative, operative, and postoperative variables were retrieved from the Cardiovascular Information Registry, which has been approved for research by the institutional review board. Mean patient age was $67 \pm 12$ years (Table 1 ). The most common indication for operation was mitral valve disease (69\%).

AF was classified as paroxysmal (27\%), persistent (14\%), or permanent $(56 \%)^{13} ; 2.1 \%$ of patients had atrial flutter as their primary arrhythmia. Median duration of preoperative AF was 24 months (range, 1-612 months). Mean left atrial diameter was $5.1 \pm$ $0.9 \mathrm{~cm}$. Preoperative treatment of AF consisted of antiarrhythmic medications $(\mathrm{n}=147$ [29\%]), warfarin $(\mathrm{n}=215$ [42\%]), and electrical cardioversion $(n=69$ [13\%]). Preoperative thromboembolic events included transient ischemic attack (10\%), stroke (9\%), and other systemic embolism (2\%).

\section{AF Ablation \\ Bipolar RF. All patients underwent AF ablation with the Atri- cure (West Chester, Ohio) bipolar RF system. In this system, electrodes reside in the jaws of an atraumatic clamp. Energy delivery is continued until tissue conductance between electrodes decreases and reaches a steady state for 2 seconds, indicating transmural conduction block. ${ }^{8,9}$}

Lesion sets. Ablation was generally performed after cardiac arrest but before the principal operative procedure. Lesion sets varied over time and were performed at the discretion of the surgeon in a nonrandomized fashion (see Electronic Appendix 


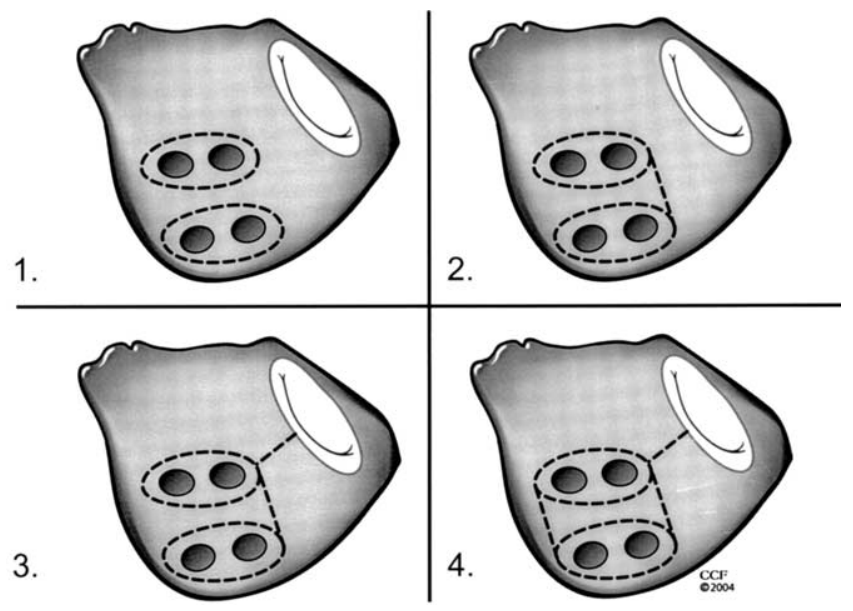

Figure 1. Schematic representation of left atrial lesion sets created with bipolar RF. White ovals represent mitral valve, sets of 4 black ovals represent pulmonary veins, and dashed lines represent sites of ablation. All ablation lesions are created with bipolar RF, except in lesion sets 3 and 4, in which the lesion connecting the left pulmonary vein lesion to the mitral valve annulus is created with cryothermy.

Figure E1). Four basic lesion sets were used most commonly, and these were termed lesion sets 1, 2, 3, and 4 (Figure 1). In all patients, pulmonary veins were isolated with the bipolar RF clamp.

Left atrial connecting lesions (lesion sets 2, 3, and 4) were created with the bipolar clamp by opening the left atrium and placing one jaw on the endocardium and one on the epicardium. The lesion connecting the left pulmonary veins to the mitral annulus (left atrial isthmus, lesion sets 3 and 4) was created by using cryothermy (Cooper Surgical, Shelton, Conn). The left atrial appendage was excluded or excised in all patients. Some patients in each group had connecting lesions from the left atrial appendage to the left pulmonary veins. One hundred seventy-five (34\%) patients received a cryothermy lesion on the right atrial isthmus.

There were differences between patients receiving different lesion sets. Compared with those receiving lesion set 1 , patients receiving lesion sets 2,3 , and 4 were more likely to have a mitral valve procedure; in addition, those receiving lesion sets 3 and 4 were less likely to have paroxysmal AF. Compared with patients receiving lesion set 1 , patients with permanent $\mathrm{AF}$ receiving lesion sets 2, 3, and 4 were more likely to have mitral valve disease and left atrial enlargement and less likely to have coronary artery disease (see Electronic Appendixes 1-4).

\section{Follow-up}

Postoperative electrocardiograms (ECGs) were used to assess AF. ECGs were performed routinely before discharge and at the discretion of referring physicians during follow-up. Recommended ECG follow-up intervals were 1 month, 3 months, 6 months, 1 year, and annually thereafter. A total of 3495 postoperative ECGs were retrieved. Every patient had at least one record available for analysis (range, 1 day to 25 months). One hundred ninety-five patients had an ECG 6 months or more after operation (Figure 2

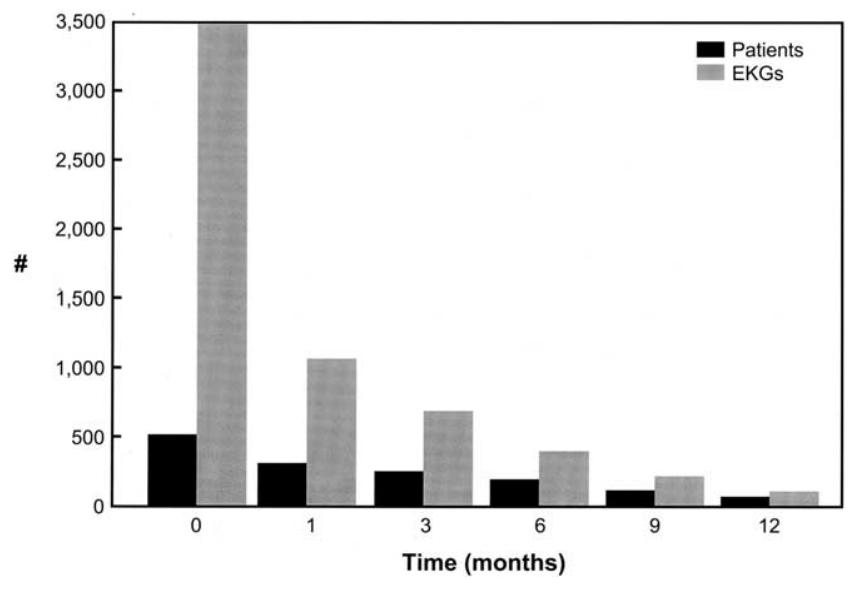

Figure 2. Number of patients with ECG follow-up available at and beyond various time points and number of ECGs available for analysis at and beyond these same time points.

and see Electronic Appendix 5, available at www.mosby.com/ jtcvs). For purposes of analysis, any one of the following 3 rhythms was considered as postoperative AF: AF, atrial flutter, or a paced rhythm with underlying AF or atrial flutter.

Clinical follow-up for survival, morbid events, and medication history was obtained by using patient visit and systematic telephone or mailed questionnaires at 3, 6, and 12 months. Median clinical follow-up was 7 months, with a total of 317 patient-years available for analysis. Use of class I and III antiarrhythmic drugs and warfarin was recorded at each follow-up. Patients were questioned concerning recurrence of AF; however, only those episodes identified by means of ECG were entered into the analyses.

\section{Analysis and Depiction of Data}

Prevalence of and risk factors for AF. Because there is no practical method for continuous heart rhythm assessment, a novel statistical technique was developed to depict the prevalence of AF versus time on the basis of discrete ECG recordings. We attempted to solve multiple challenges simultaneously: repeated ECG recordings for each patient (repeated measures), variable times of recording, censoring by death, and a complex temporal pattern of $\mathrm{AF}$ prevalence that likely represented the variable effect of different modulating factors across time. The analytic approach taken was temporal decomposition, using several simple additive components (early, constant, and late in this instance) into which separate streams of modulating variables were incorporated for simultaneous analysis. The mathematic models used were derived from those previously used over the last 20 years for decomposition of time-to-event data. ${ }^{14}$ Longitudinal binary logistic regression analysis for repeated measurements (PROC NLMIXED, SAS, Inc, Cary, NC) was used to resolve the number of time components and to estimate the shaping parameters of each.

Multivariable analysis was performed in the odds domain to identify risk factors for each component (see Electronic Appendix 6, available at www.mosby.com/jtcvs). Because of the limited ability of PROC NLMIXED to explore multivariable relations, we screened 


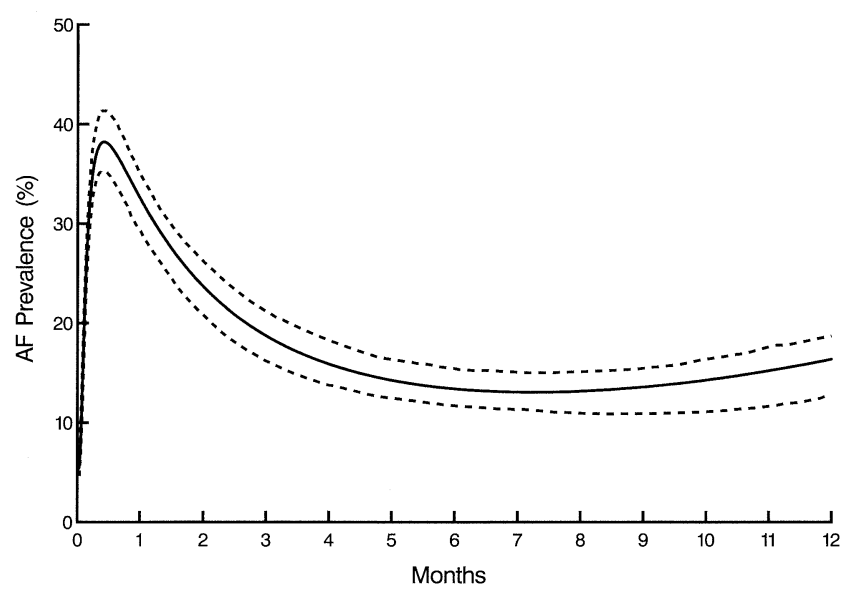

Figure 3. Temporal pattern of AF after ablation on the basis of postoperative ECGs. The solid line represents point estimates enclosed within $68 \%$ bootstrap CLs.

variables using ordinary multivariable logistic regression analysis (PROC LOGISTIC, SAS) with a liberal retention criterion $(P \leq .15)$. Candidate risk factors identified were entered at once into PROC NLMIXED and then eliminated one by one until all variables remaining had a $P$ value of .1 or less.

Ablation failure and risk factors. Ablation failure was defined as any occurrence of AF or atrial flutter 6 months or more after ablation. Therefore, to be at risk of ablation failure, patients had to have an ECG obtained in this timeframe. Patients were considered to have ablation failure even if late $\mathrm{AF}$ was transient. Data were considered interval censored, with the event assumed to occur between the time of an ECG showing AF and the immediately preceding ECG not showing AF.

To identify risk factors for ablation failure, ${ }^{14}$ a parametric model was used to resolve a number of instantaneous risks of the interval-censored event (hazard function) and to estimate shaping parameters. (For additional details, see http://www. clevelandclinic.org/heartcenter/hazard.) Variable selection was by bootstrap bagging ${ }^{15,16}$ using a retention criterion of $P$ less than .05 and considering variables appearing in $50 \%$ or more models as reliably significant at this level.

\section{Presentation}

Predicted percentages of prevalence of AF and freedom-fromevent curves are accompanied by asymmetric $68 \%$ confidence limits (CLs) comparable to $\pm 1 \mathrm{SE}$.

\section{Results}

\section{In Hospital}

There were no ablation device-related complications. Hospital morbidity included stroke in $8(2 \%)$ patients, transient ischemic attack in $4(1 \%)$, and reoperation for bleeding in $25(5 \%)$. Strokes were judged to be related to the patient's underlying disease (atherosclerosis or calcified valvular heart disease requiring extensive debridement). There were 10 hospital deaths (2\%; CL, $1.3 \%-2.8 \%$ ).
TABLE 2. Incremental risk factors for higher prevalence of atrial fibrillation

\begin{tabular}{lcc}
\hline Risk factor & Estimate \pm SE & $P$ value \\
\hline $\begin{array}{l}\text { Overall } \\
\quad \text { Preoperative permanent AF vs }\end{array}$ & $0.89 \pm 0.20$ & $<.0001$ \\
$\quad$ paroxysmal & & \\
$\quad$ Preoperative persistent AF vs & $0.080 \pm 0.27$ & .8 \\
$\quad$ paroxysmal & & \\
$\quad$ Greater ventricular wall stress* & $-0.67 \pm 0.16$ & $<.0001$ \\
$\quad$ Larger left atrial diametert & $-1.2 \pm 0.51$ & .02 \\
$\quad$ Thinner septum $~$ & $1.1 \pm 0.57$ & .06 \\
Early phase & & \\
$\quad$ Older age§ & $-1.5 \pm 0.52$ & .004 \\
$\quad$ Greater aortic valve regurgitation & $0.21 \pm 0.082$ & .01 \\
$\quad$ Lesion set 2 vs 1 & $0.46 \pm 0.27$ & .09 \\
$\quad$ Lesion sets 3 or 4 vs 1 & $0.19 \pm 0.23$ & .4 \\
Constant phase & & \\
$\quad$ None & & \\
Late phase & & \\
$\quad$ Lesion set 2 and permanent AF & $0.54 \pm 0.23$ & .02 \\
\hline
\end{tabular}

$A F$, Atrial fibrillation. *(1/relative wall thickness), inverse transformation. $\dagger(5 /$ left atrial diameter $)$, inverse transformation. $\$(1 /$ septal thickness $)$, inverse transformation. $\S(70 /$ age $)$, inverse transformation.

\section{Heart Rhythm}

Prevalence of AF and its risk factors. A curve demonstrating the time-related predicted prevalence of AF or atrial flutter after operation is depicted in Figure 3. Early prevalence of AF peaked at 38\% (CL, 35\%-41\%) at 2 weeks. By 6 months, the prevalence decreased to $13 \%$ (CL, 12\%-15\%), gradually increasing thereafter to $16 \%(\mathrm{CL}, 13 \%-19 \%)$ at 1 year. At 6 months, $26 \%$ of patients were taking antiarrhythmic medications (see Figure E2), and 50\% were taking warfarin (see Figure E3).

Temporal decomposition of AF prevalence yielded 3 time phases (see Figure E4), and multivariable analysis identified different factors modulating each (Table 2). Because the number of ECGs collected for patients receiving lesion set 4 was low after 6 months, lesion sets 3 and 4 were combined as one set for all analyses.

Preoperative permanent AF (Figure 4, A) and larger left atrial diameter (see Figure E5) were associated with increased prevalence of AF. All lesion sets achieved similar results with paroxysmal AF (Figure 4,C), but lesion set 2 was associated with increased prevalence of $\mathrm{AF}$ in patients with permanent AF (Figure 4,C).

Ablation failure. One hundred ninety-five patients had ECGs obtained 6 or more months after ablation and were therefore at risk for ablation failure (see the "Materials and Methods" section). Ablation failure occurred in 53 patients; mode of failure was AF in 41 and atrial flutter in 12. Freedoms from ablation failure were $72 \%$ at 12 months and $66 \%$ at 18 months (Figure 5). Risk factors for ablation 

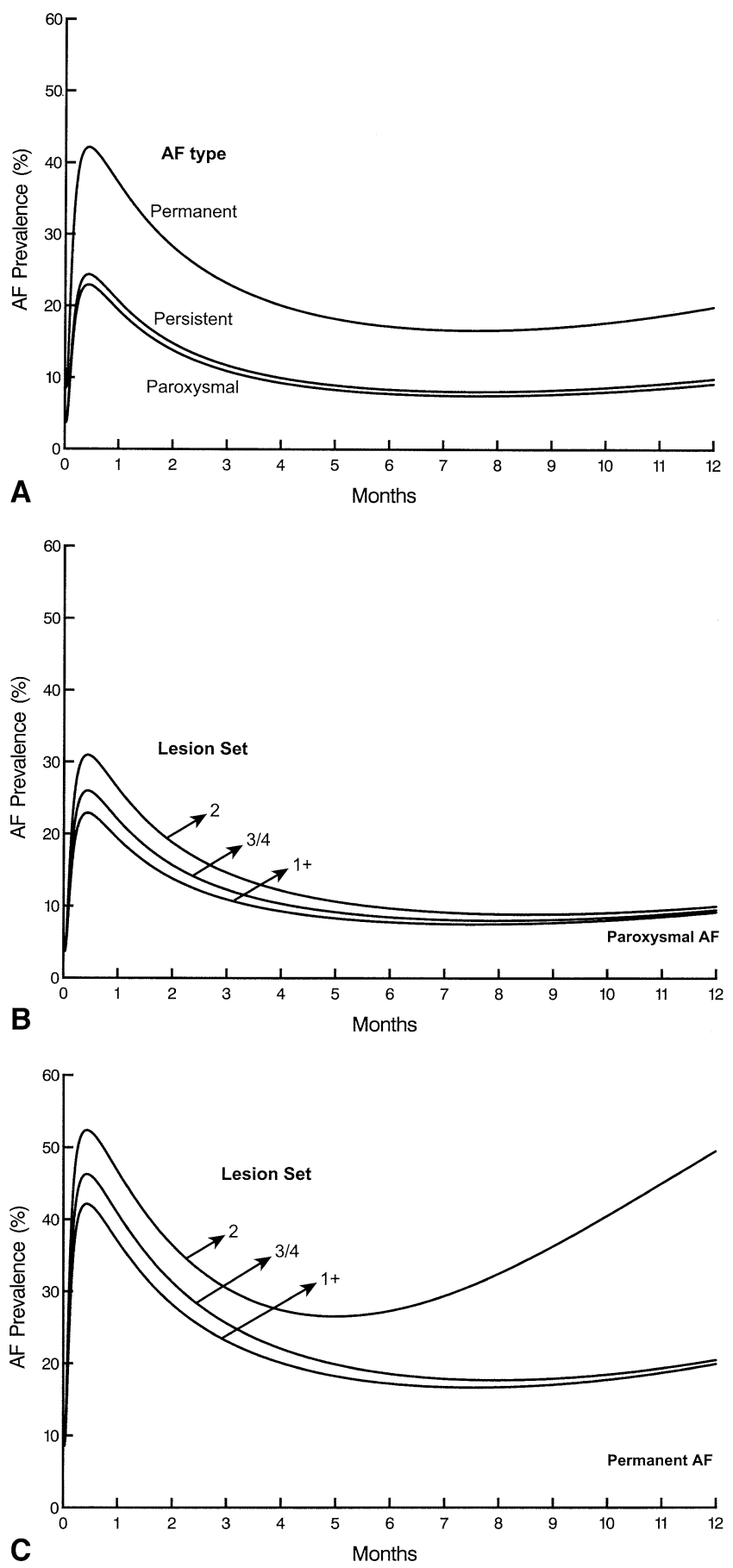

Figure 4. Nomograms from the multivariable equation (Table 2) demonstrating effects of factors on prevalence of AF. A, Type of AF. B, Lesion set in paroxysmal AF. There is no difference between lesions sets. C, Lesion set in permanent AF. Note that 1+ refers to both lesion set 1 and miscellaneous additional lesions, generally to the left atrial appendage. Results with lesion set 2 are inferior.

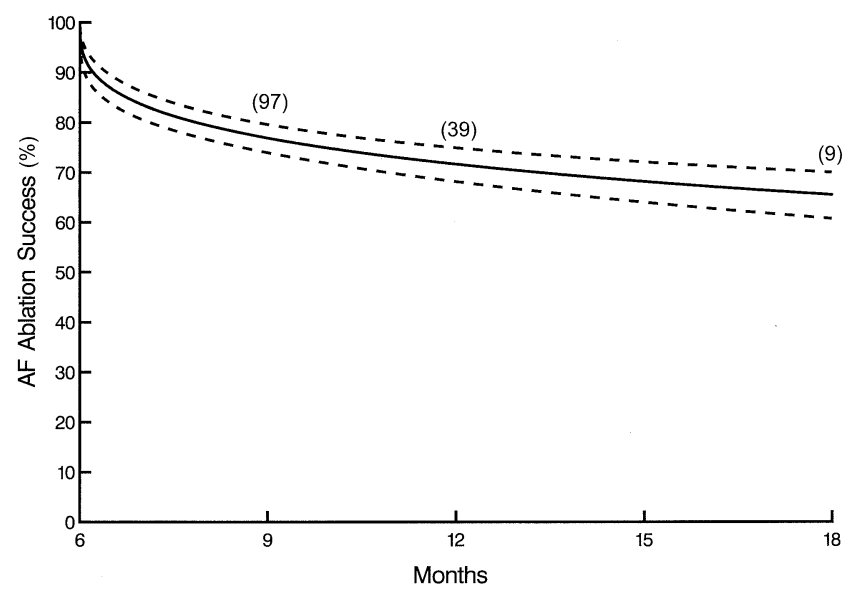

Figure 5. Freedom from ablation failure. The solid line represents parametric estimate enclosed within dashed $68 \%$ CLs. Numbers in parentheses represent patients remaining at risk. The horizontal scale begins at $\mathbf{6}$ months postoperatively because patients are not at risk for ablation failure until that time.

failure included longer duration of preoperative AF, larger left atrial diameter, and use of lesion set 2 in patients with permanent AF (Table 3 and see Figure E6).

\section{Discussion}

Key Findings

This report documents early results with application of bipolar RF to facilitate AF ablation in cardiac surgical patients. Key findings are that (1) the prevalence of AF peaks early after surgical intervention and then decreases to $16 \%$ at 1 year, (2) freedom from ablation failure is $72 \%$ at 12 months, and (3) recurrence of AF is influenced by the type and duration of AF, the choice of lesion set in permanent $\mathrm{AF}$, and left atrial size.

\section{AF in Cardiac Surgical Patients}

The rationale for restoring sinus rhythm in patients presenting for cardiac surgery includes (1) improving survival, (2)

\section{TABLE 3. Risk factors for ablation failure}

\begin{tabular}{lrcc}
\hline Risk factor & Estimate \pm SE & $\boldsymbol{P}$ value & $\mathbf{R}(\%)^{*}$ \\
\hline Lesion set 2 and permanent AF & $1.1 \pm 0.33$ & .001 & 92 \\
Longer duration of & $0.29 \pm 0.12$ & .01 & 70 \\
$\quad$ preoperative AF† & & & \\
Larger left atrial diameter $\ddagger$ & $-2.1 \pm 0.97$ & .03 & 49 \\
Greater wall stress§ & $1.3 \pm 0.62$ & .03 & 43
\end{tabular}

$A F$, Atrial fibrillation. *Reliability: percentage of occurrences in bootstrap models. $\dagger$ Ln(duration of $A F+1)$, logarithmic transformation. $\ddagger(5 /$ left atrial diameter), inverse transformation. $\S$ (Relative wall thickness) ${ }^{2}$, squared transformation. 
reducing risk of stroke and other systemic embolism, (3) eliminating need for anticoagulation, (4) reducing symptoms associated with tachycardia, and (5) improving cardiac output. ${ }^{1-3}$ Because most of these patients do not revert to sinus rhythm with treatment of their primary cardiac lesion (with the possible exception of AF of short duration), we took an aggressive approach to ablation. ${ }^{17}$

Although the Cox maze III procedure restores sinus rhythm or an atrioventricular paced rhythm in $75 \%$ to $95 \%$ of patients undergoing concomitant cardiac surgery, ${ }^{1-5}$ it has not been widely performed. Recently, there has been great interest in treating AF surgically, which is attributable to increased understanding of its pathogenesis and development of new ablation technologies. In most patients, triggers and substrates for AF are located in the left atrium and pulmonary veins, ${ }^{12}$ and therefore ablation is now focused on these areas. Alternative energy sources enable rapid creation of lines of conduction block without the laborious cutting and sewing of the Cox maze III procedure. Reported ablation success ranges from $60 \%$ to $95 \%$ using a variety of different energy sources and lesion sets in various types of patients. ${ }^{6,7,10,11}$ However, there are few data identifying patient- and procedure-related risk factors for ablation failure, and no valid statistical technique to assess results. ${ }^{7}$

\section{Prevalence of AF, Ablation Failure, and Risk Factors} In the current study, bipolar RF was the predominant modality used to create left atrial lesions; cryothermy was used to create lesions on the right and left atrial isthmuses in some patients. Four basic left atrial lesion sets were used. This variability in lesion sets, coupled with varying patient characteristics and types and durations of $\mathrm{AF}$, facilitated identification of risk factors for return of $\mathrm{AF}$ and ablation failure.

Risk factors for AF prevalence and ablation failure were both patient and procedure related. Longer duration of $\mathrm{AF}$, permanent $\mathrm{AF}$, and larger left atrial diameter increased either the prevalence of $\mathrm{AF}$, the risk of ablation failure, or both. In fact, these characteristics tended to occur together in the same patients. Others have demonstrated increased risk of ablation failure when these factors were present. ${ }^{18-22}$ These findings suggest that it is unlikely that "one size fits all" in ablating $\mathrm{AF}^{23}$; rather, a tailored approach is indicated.

Procedural risk factors were related to choice of lesion set. In patients with paroxysmal and persistent AF, all lesion sets produced equivalent results. Each lesion set included pulmonary vein isolation, suggesting that drivers of AF in these patients might reside in the pulmonary veins. In contrast, choice of lesion set affected results in patients with permanent AF. Those who received lesion sets 2, 3, and 4 tended to have mitral valve disease and left atrial enlargement (see Electronic Appendix 4 available at www.mosby. com/jtcvs). Lesion set 2, which does not include a lesion to the mitral annulus, produced inferior results in these patients compared with lesion sets 3 and 4 . It has been suggested that failure to ablate the left atrial isthmus jeopardizes success. $^{24,25}$ Our results support this concept in patients with mitral valve disease. As in previous reports, addition of right atrial lesions (eg, isthmus lesions) did not affect results. ${ }^{26}$

Others have reported that lesion set affects results. Gaynor and colleagues ${ }^{27}$ found that the Cox maze III procedure was more effective than the Cox maze I and II. Data from catheter-based procedures in patients with paroxysmal $\mathrm{AF}$ suggest that the more left atrial area isolated, the better the freedom from $\mathrm{AF}^{28-30}$

\section{Limitations}

This series contains early follow-up of a large cohort of patients undergoing intraoperative RF ablation with or without cryothermy. ECGs used for analysis were obtained routinely in the hospital but opportunistically after hospital discharge. Although only 195 patients had ECGs beyond 6 months after operation, there are a sufficient number for analysis. Patients having late ECGs might be selected because they had symptomatic $\mathrm{AF}$, leading to overestimation of the prevalence of $\mathrm{AF}$ and ablation failure. Alternatively, asymptomatic AF episodes without ECG verification might have been missed, leading to underestimation of events. ${ }^{31}$ Although periodic Holter monitoring and event recorders would have provided more data for analysis, these methodologies might still fail to capture all $\mathrm{AF}$ episodes. Limitations in the ability to document heart rhythm continuously over time led us to develop novel statistical methods that we believe provide accurate estimates of $\mathrm{AF}$ prevalence. Although not perfect, this method represents an important improvement over analyses relying on rhythm at last follow-up or patient self-reporting.

Results of AF ablation were assessed and presented in 2 related but different fashions. We estimated the prevalence of $\mathrm{AF}$ to depict the predicted prevalence of $\mathrm{AF}$ in the population at any given time after ablation. In such a depiction, a given patient might have AF on one ECG and sinus rhythm on the next, unlike in a time-to-event analysis. We also estimated freedom from ablation failure, with ablation failure defined as any recurrence of AF beyond 6 months after operation. Although this definition is stringent, it is appropriate.

The analyses of prevalence of AF and ablation failure do not take into account antiarrhythmic medications that patients might have been taking. The prevalence of antiarrhythmic medication use is depicted separately. Although we recommend discontinuing antiarrhythmic agents 3 months after ablation, continued use is at the discretion of referring cardiologists, which hampered our ability to report the prevalence of $\mathrm{AF}$ and freedom from ablation failure off medications. 
We did not assess lesion integrity using pacing or other methods; it is therefore possible that operator error or other factors might have resulted in some patients receiving incomplete lesions, which might have contributed to ablation failures.

\section{Clinical Inferences}

$\mathrm{AF}$ is common early but is transient after intraoperative ablation. Early operation after the development of AF and left atrial size reduction in those with enlarged left atria might improve results. In patients with paroxysmal and persistent AF, simple pulmonary vein isolation might be adequate. In patients with permanent $\mathrm{AF}$, we recommend the left atrial lesion set of the Cox maze III procedure. A prospective randomized clinical trial with longer follow-up is necessary to test these strategies.

\section{References}

1. Bando K, Kasegawa H, Okada Y. The impact of pre- and postoperative atrial fibrillation on outcome after mitral valvuloplasty for nonischemic mitral regurgitation. J Thorac Cardiovasc Surg. 2004. In press.

2. Bando K, Kobayashi J, Kosakai Y, Hirata M, Sasako Y, Nakatani S, et al. Impact of Cox maze procedure on outcome in patients with atrial fibrillation and mitral valve disease. J Thorac Cardiovasc Surg. 2002; 124:575-83.

3. Cox JL. Intraoperative options for treating atrial fibrillation associated with mitral valve disease. J Thorac Cardiovasc Surg. 2001;122:212-5.

4. McCarthy PM, Gillinov AM, Castle L, Chung M, Cosgrove D 3rd. The Cox-Maze procedure: the Cleveland Clinic experience. Semin Thorac Cardiovasc Surg. 2000;12:25-9.

5. Ad N, Cox JL. Combined mitral valve surgery and the maze III procedure. Semin Thorac Cardiovasc Surg. 2002;14:206-9.

6. Damiano RJ Jr. Alternative energy sources for atrial ablation: judging the new technology. Ann Thorac Surg. 2003;75:329-30.

7. Gillinov AM, Blackstone EH, McCarthy PM. Atrial fibrillation: current surgical options and their assessment. Ann Thorac Surg. 2002;74: 2210-7.

8. Gillinov AM, McCarthy PM. AtriCure bipolar radiofrequency clamp for intraoperative ablation of atrial fibrillation. Ann Thorac Surg. 2002;74:2165-8.

9. Prasad SM, Maniar HS, Schuessler RB, Damiano RJ Jr. Chronic transmural atrial ablation by using bipolar radiofrequency energy on the beating heart. J Thorac Cardiovasc Surg. 2002;124:708-13.

10. Sie HT, Beukema WP, Elvan A, Ramdat Misier AR. Long-term results of irrigated radiofrequency modified maze procedure in 200 patients with concomitant cardiac surgery: six years experience. Ann Thorac Surg. 2004;77:512-7.

11. Mohr FW, Fabricius AM, Falk V, Autschbach R, Doll N, Von Oppell $\mathrm{U}$, et al. Curative treatment of atrial fibrillation with intraoperative radiofrequency ablation: short-term and midterm results. $J$ Thorac Cardiovasc Surg. 2002;123:919-27.

12. Haissaguerre M, Jais P, Shah DC, Takahashi A, Hocini M, Quiniou G, et al. Spontaneous initiation of atrial fibrillation by ectopic beats originating in the pulmonary veins. N Engl J Med. 1998;339:659-66.

13. Fuster V, Ryden LE, Asinger RW, Cannom DS, Crijns HJ, Frye RL, et al. ACC/AHA/ESC guidelines for the management of patients with atrial fibrillation. A report of the American College of Cardiology/ American Heart Association Task Force on Practice Guidelines and the European Society of Cardiology Committee for Practice Guidelines and Policy Conferences (Committee to develop guidelines for the management of patients with atrial fibrillation) developed in collaboration with the North American Society of Pacing and Electrophysiology. Eur Heart J. 2001;22:1852-923.
14. Blackstone EH, Naftel DC, Turner ME Jr. The decomposition of time-varying hazard into phases, each incorporating a separate stream of concomitant information. J Am Stat Assoc. 1986;81:615-24.

15. Breiman L. Bagging predictors. Machine Learning. 1996;24:123-40.

16. Blackstone EH. Breaking down barriers: helpful breakthrough statistical methods you need to understand better. J Thorac Cardiovasc Surg. 2001;122:430-9.

17. Obadia JF, el Farra M, Bastien $\mathrm{OH}$, Lievre $\mathrm{M}$, Martelloni $\mathrm{Y}$, Chassignolle JF. Outcome of atrial fibrillation after mitral valve repair. J Thorac Cardiovasc Surg. 1997;114:179-85.

18. Kobayashi J, Kosakai Y, Nakano K, Sasako Y, Eishi K, Yamamoto F. Improved success rate of the maze procedure in mitral valve disease by new criteria for patients' selection. Eur J Cardiothorac Surg. 1998; 13:247-52.

19. Scherer M, Dzemali O, Aybek T, Wimmer-Greinecker G, Moritz A. Impact of left atrial size reduction on chronic atrial fibrillation in mitral valve surgery. J Heart Valve Dis. 2003;12:469-74.

20. Zembala M, Lenarczyk R, Kalarus Z, Puszczewicz D, Przybylski R, Pacholewicz J. Early and late outcome after microwave ablation for chronic valvular atrial fibrillation. Heart Surg Forum. 2003;6: 403-8.

21. Chen MC, Chang JP, Guo GB, Chang HW. Atrial size reduction as a predictor of the success of radiofrequency maze procedure for chronic atrial fibrillation in patients undergoing concomitant valvular surgery. J Cardiovasc Electrophysiol. 2001;12:867-74.

22. Kosakai Y, Kawaguchi AT, Isobe F, Sasako Y, Nakano K, Eishi K, et al. Cox maze procedure for chronic atrial fibrillation associated with mitral valve disease. J Thorac Cardiovasc Surg. 1994;108: 1049-55.

23. Haines DE. With pulmonary vein isolation for paroxysmal atrial fibrillation ablation, one size does not fit all. $J$ Cardiovasc Electrophysiol. 2002;13:962-3.

24. Luria DM, Nemec J, Etheridge SP, Compton SJ, Klein RC, Chugh SS, et al. Intra-atrial conduction block along the mitral valve annulus during accessory pathway ablation: evidence for a left atrial "isthmus." J Cardiovasc Electrophysiol. 2001;12:744-9.

25. Cox JL, Ad N. The importance of cryoablation of the coronary sinus during the maze procedure. Semin Thorac Cardiovasc Surg. 2000;12: 20-4.

26. Deneke T, Khargi K, Grewe PH, von Dryander S, Kuschkowitz F, Lawo T, et al. Left atrial versus bi-atrial Maze operation using intraoperatively cooled-tip radiofrequency ablation in patients undergoing open-heart surgery: safety and efficacy. J Am Coll Cardiol. 2002;39: 1644-50.

27. Gaynor SL, Schuessler RB, Bailey MS, Ishii Y, Boineau JP, Gleva MJ, et al. Surgical treatment of atrial fibrillation: predictors of late recurrence. J Thorac Cardiovasc Surg. 2005;129:104-11.

28. Pappone C, Santinelli V, Manguso F, Vicedomini G, Gugliotta F, Augello G, et al. Pulmonary vein denervation enhances long-term benefit after circumferential ablation for paroxysmal atrial fibrillation. Circulation. 2004;109:327-34.

29. Oral H, Scharf C, Chugh A, Hall B, Cheung P, Good E, et al. Catheter ablation for paroxysmal atrial fibrillation: segmental pulmonary vein ostial ablation versus left atrial ablation. Circulation. 2003;108:2355-60.

30. Marrouche NF, Dresing T, Cole C, Bash D, Saad E, Balaban K, et al. Circular mapping and ablation of the pulmonary vein for treatment of atrial fibrillation: impact of different catheter technologies. J Am Coll Cardiol. 2002;40:464-74.

31. Pacifico A, Henry PD. Ablation for atrial fibrillation: are cures really achieved? J Am Coll Cardiol. 2004;43:1940-2.

\section{Discussion}

Dr Donald B. Doty (Salt Lake City, Utah). Dr Gillinov and his associates have provided us with information on a large series of patients, 513, having ablation procedures with bipolar RF for the treatment of AF during slightly more than a 2-year period. It is a retrospective study and is subject to all of the problems associated 
with such studies. One, there was no protocol or agreement as to the lesion pattern in these patients. Choice was by surgeon discretion, and the lesion pattern changed and evolved over time. The patients were classified according to established American Heart Association and American College of Cardiology criteria: paroxysmal, meaning easily or spontaneously converted to normal sinus rhythm; persistent, probably can be converted; and permanent, cannot be converted. But the lesion pattern choice was apparently not consistently applied by category of patient.

The title of the article implies that bipolar RF energy was the energy used to create left atrial ablation lesions, but the data show that patients having lesion patterns 3 and 4 had the left atrial isthmus lesion created by means of cryothermia and that one third of the patients had right atrial inferior isthmus ablation lesions created by means of cryothermia, presumably to prevent postoperative atrial flutter.

Data have been analyzed by using complex statistical methods in an attempt to compensate for events occurring over time and in which they used analysis of ECGs obtained nearly randomly in the postoperative period. Terms such as longitudinal binary logistic regression analysis and bootstrap bagging are used. Now Gene Blackstone has explained this to me on frequent occasions, making nearly perfect logical sense, and I accept these methods knowing Gene Blackstone is correct, although I confess I really do not understand them very well, and I am not even going to ask Marc to try to explain them to us.

Dr Gillinov. But I am ready to explain them.

Dr Doty. Well, you do not have to. We accept them. And I think the authors have done a very good job of making some sense out of some difficult data, nearly 3500 ECGs. Let me give you what my interpretation of these data is based on reading the article and hearing what is presented, which quite accurately matches the article. Except for the connecting lesion, lesion patterns 1 and 2 are the same. These are patients who had in common pulmonary vein isolation lesions, and they worked well with the paroxysmal or persistent types of AF, in which one would expect trigger points in the pulmonary veins to initiate the arrhythmia. Lesion pattern 2 added the connecting lesion, but this was not enough when it came to permanent forms, and it has biased the data because the patients who had lesion pattern 2 were heavily weighed with patients with mitral valve disease, whereas the patients with lesion pattern 1 were not, and therefore one would expect the data to come out that way because the substrate for patients receiving lesion pattern 2 implies a much more complex pathogenesis of the AF than trigger points in the left pulmonary veins.

Now lesion patterns 3 and 4 are also the same, having in common pulmonary vein isolation and left atrial isthmus lesions, except that lesion pattern 4 has a double connecting lesion, which, by the way, leads to a portion of the left atrial posterior wall isolated from any electrical depolarization. And this appears to be a more effective lesion pattern when the left atrium is abnormal, such as in mitral valve disease. We do not know from the data, and we have not heard anything presented, what the effect of right atrial isthmus lesions, which were done by means of cryothermia in about one third of these patients, might be, and I would say that the conclusion of the authors, proposed effect of left atrial reduction, is purely speculative because there are no data in this presentation or the article on which you can base that conclusion.

The first question is as follows: What is the added cost of using 2 energy sources for this operation? Second, what is the role of the right atrial isthmus ablation in the treatment of AF? Three, should pulmonary vein isolation lesions be restricted to patients having paroxysmal forms or perhaps persistent forms of AF? And finally, what is the currently recommended lesion pattern for permanent forms of AF?

Dr Gillinov. Thank you, Dr Doty, for all of your comments. I think the preamble to your questions hits on something that can be used as the strength of this presentation. It is incredibly heterogeneous. There were 10 surgeons handling many different types of patients with different lesion sets in different approaches. At first glance that might produce just chaos, but on the other hand, if you have enough patients and enough followup, it allows you to discern patterns that relate to both the sort of patients and the lesions created, and you can get the beginnings of some answers, and therefore the heterogeneity was useful.

Regarding the cost of the 2 energy sources? Well, it is higher than we would like, but we used the older reusable cryo system, so that is a sunk cost from 15 years ago. It does not cost us anything additional to use the Cooper Surgical or Frigitronics system once we have already purchased it, and therefore we are paying for only one disposable ablation unit per case. There are people who create the isthmus lesion with RF. We have not because of fear of injury to the circumflex artery, although I am not sure that has been reported.

What about the right atrial isthmus lesion? We analyzed that to determine whether its presence or absence is a risk factor for failure. In our experience the answer is that no, it has no effect, and therefore we create one now only in someone who has a history of flutter.

Should pulmonary vein isolation be restricted to patients with paroxysmal AF? Not entirely. Pulmonary vein isolation is now our lesion set of choice with excision of the appendage in the paroxysmal patient. However, in patients who are very ill and who undergo a complex operation in which we do not want to spend even the additional 10 minutes to open the atrium and create connecting lesions, we will just do the pulmonary veins, and about $40 \%$ or $50 \%$ of those might have some success. On the other hand, if a patient has permanent $\mathrm{AF}$ and there is no specific contraindication or difficulty to opening the atrium and making connecting lesions, then our lesion set of choice in the left atrium looks like a maze procedure.

Dr Vaughn Starnes (Los Angeles, Calif). It is not only a very heterogeneous group of surgeons but also a heterogeneous population of patients.

My question pertains to the mitral valve repair itself. Did the repair and durability of that repair affect in any way the results of your AF; that is, if you had some residual mitral regurgitation or regurgitation developed, did it affect your outcome?

Dr Gillinov. I do not know whether recurrent mitral regurgitation influences the results; it very well might. Because recurrent mitral regurgitation and return of $\mathrm{AF}$ are both time-related outcomes of the surgical procedure, analysis of their relationship is statistically challenging. 


\begin{tabular}{|c|c|c|c|c|c|}
\hline \multirow[b]{2}{*}{ Characteristic } & \multicolumn{4}{|c|}{ Lesion set } & \multirow[b]{2}{*}{$P$ value } \\
\hline & $\begin{array}{c}\text { 1, n }=194(38 \%) \\
\text { No. }(\%)\end{array}$ & $\begin{array}{c}2, n=96(19 \%), \\
\text { No. }(\%)\end{array}$ & $\begin{array}{c}3 / 4, n=183(36 \%) \\
\text { No. }(\%)\end{array}$ & $\begin{array}{c}\text { Other, } \mathbf{n}=\mathbf{4 0}(8 \%) \text {, } \\
\text { No. }(\%)\end{array}$ & \\
\hline \multicolumn{6}{|l|}{ Demographic } \\
\hline Male & $122(63)$ & $54(56)$ & $94(51)$ & $28(70)$ & .05 \\
\hline \multicolumn{6}{|l|}{ Cardiac comorbidity } \\
\hline NYHA functional class & & & & & .4 \\
\hline I & $30(15)$ & $18(19)$ & $38(21)$ & $7(18)$ & \\
\hline II & $106(55)$ & $51(53)$ & $109(60)$ & $27(68)$ & \\
\hline III & $50(26)$ & $23(24)$ & $32(17)$ & $6(15)$ & \\
\hline IV & $8(4)$ & $4(4)$ & $4(2)$ & $0(0)$ & \\
\hline Emergency operation & $4(2)$ & $0(0)$ & $0(0)$ & $0(0)$ & .08 \\
\hline Left main disease* & $21(11)$ & $7(7)$ & $4(2)$ & $2(5)$ & .007 \\
\hline LAD disease $e^{*}$ & $82(45)$ & $30(32)$ & $38(21)$ & $15(39)$ & $<.0001$ \\
\hline Circumflex disease ${ }^{*}$ & $65(35)$ & $23(24)$ & $34(19)$ & $11(29)$ & .006 \\
\hline Right coronary disease* & $75(41)$ & $25(27)$ & $34(19)$ & $10(26)$ & $<.0001$ \\
\hline Previous cardiac operation & & & & & .5 \\
\hline 0 & $160(82)$ & $78(81)$ & $156(85)$ & $32(80)$ & \\
\hline 1 & $28(14)$ & $16(17)$ & $24(13)$ & $8(20)$ & \\
\hline 2 & $6(3)$ & $1(1)$ & $3(1.6)$ & $0(0)$ & \\
\hline 3 & $0(0)$ & $1(1)$ & $0(0)$ & $0(0)$ & \\
\hline Previous myocardial infarction & $74(38)$ & $22(23)$ & $32(17)$ & $13(32)$ & $<.0001$ \\
\hline Mitral valve disease cause & $90(46)$ & $74(77)$ & $152(83)$ & $38(95)$ & \\
\hline Degenerative $\dagger$ & $44(49)$ & $47(64)$ & $99(65)$ & $21(55)$ & .07 \\
\hline Rheumatic $†$ & $19(21)$ & $17(23)$ & $34(22)$ & $6(16)$ & .8 \\
\hline Ischemict & $17(19)$ & $7(9)$ & $5(3)$ & $7(18)$ & .0004 \\
\hline Endocarditis $†$ & $0(0)$ & $1(1)$ & $1(0.66)$ & $0(0)$ & .7 \\
\hline Functional† & $4(4)$ & $1(1.3)$ & $10(5)$ & $1(3)$ & .3 \\
\hline Radiationt & $1(1)$ & $0(0)$ & $1(0.7)$ & $0(0)$ & .8 \\
\hline Prosthetic valve dysfunctiont & $5(6)$ & $1(1.3)$ & $1(0.7)$ & $3(8)$ & .03 \\
\hline Unspecified & $0(0)$ & $0(0)$ & $1(0.7)$ & $0(0)$ & .7 \\
\hline Mitral regurgitation grade & & & & & $<.0001$ \\
\hline 0 & $38(20)$ & $13(14)$ & $15(8)$ & $1(2.5)$ & \\
\hline $1+$ & $38(20)$ & $14(15)$ & $17(9)$ & $1(2.5)$ & \\
\hline $2+$ & $33(17)$ & $9(9)$ & $19(10)$ & $6(15)$ & \\
\hline $3+$ & $31(16)$ & $23(24)$ & $46(25)$ & $8(20)$ & \\
\hline $4+$ & $53(27)$ & $37(38)$ & $86(47)$ & $24(60)$ & \\
\hline \multicolumn{6}{|l|}{ Atrial fibrillation type } \\
\hline Permanent & $101(52)$ & $45(47)$ & $121(66)$ & $22(55)$ & .007 \\
\hline Persistent & $25(13)$ & $13(14)$ & $29(16)$ & $7(18)$ & .8 \\
\hline Paroxysmal & $65(34)$ & $35(36)$ & $29(16)$ & $10(25)$ & .0002 \\
\hline Flutter & $3(1.6)$ & $3(3)$ & $4(2)$ & $1(2.5)$ & .9 \\
\hline \multicolumn{6}{|l|}{ Noncardiac comorbidity } \\
\hline Hypertension & $131(68)$ & $62(65)$ & $110(61)$ & $24(60)$ & .5 \\
\hline \multicolumn{6}{|l|}{ Preoperative thromboembolic event } \\
\hline Syncope & $22(11)$ & $9(9)$ & $15(8)$ & $3(8)$ & .7 \\
\hline Transient ischemic attack & $20(10)$ & $7(7)$ & $17(9)$ & $5(12)$ & .8 \\
\hline Cerebrovascular accident & $24(12)$ & $6(6)$ & $16(9)$ & $2(5)$ & .2 \\
\hline Embolus & $3(1.6)$ & $1(1)$ & $5(3)$ & $0(0)$ & 6 \\
\hline \multicolumn{6}{|l|}{ Procedure } \\
\hline Mitral valve repair & $54(28)$ & $46(48)$ & $103(56)$ & $24(60)$ & $<.0001$ \\
\hline Mitral valve replacement & $36(19)$ & $28(29)$ & $49(27)$ & $14(35)$ & .05 \\
\hline Aortic valve replacement & $76(39)$ & $35(36)$ & $46(25)$ & $7(18)$ & .004 \\
\hline Tricuspid valve repair & $50(26)$ & $23(24)$ & $52(28)$ & $8(20)$ & .7 \\
\hline Isolated CABG & $31(16)$ & $4(4)$ & $3(2)$ & $1(2)$ & $<.0001$ \\
\hline Any CABG & $92(47)$ & $35(36)$ & $50(27)$ & $18(45)$ & .0007 \\
\hline
\end{tabular}




\begin{tabular}{|c|c|c|c|c|c|}
\hline \multirow[b]{2}{*}{ Characteristic } & \multicolumn{4}{|c|}{ Lesion set } & \multirow[b]{2}{*}{$P$ value } \\
\hline & $\begin{array}{c}\text { 1, n }=194(38 \%) \\
\text { No. }(\%)\end{array}$ & $\begin{array}{c}2, n=96(19 \%) \\
\text { No. }(\%)\end{array}$ & $\begin{array}{c}3 / 4, n=183(36 \%) \\
\text { No. }(\%)\end{array}$ & $\begin{array}{c}\text { Other, } n=40(8 \%), \\
\text { No. }(\%)\end{array}$ & \\
\hline \multicolumn{6}{|l|}{ Lesion } \\
\hline Right atrial lesion & $9(5)$ & $8(8)$ & $141(77)$ & $17(42)$ & $<.0001$ \\
\hline
\end{tabular}

Electronic Appendix 2. Patient characteristics according to lesion set: continuous variables*

\begin{tabular}{|c|c|c|c|c|c|}
\hline \multirow[b]{2}{*}{ Characteristic } & \multicolumn{4}{|c|}{ Lesion set } & \multirow{2}{*}{$\begin{array}{c}P \\
\text { valuet }\end{array}$} \\
\hline & 1 & 2 & $3 / 4$ & Other & \\
\hline \multicolumn{6}{|l|}{ Demographic } \\
\hline Age (y) & $68 \pm 12$ & $67 \pm 12$ & $67 \pm 11$ & $64 \pm 13$ & .08 \\
\hline \multicolumn{6}{|l|}{ Cardiac comorbidity } \\
\hline Duration of $A F(m o) \ddagger$ & $3,24,84$ & $3,31,100$ & $4,36,120$ & $2,13,60$ & .006 \\
\hline LV end-diastolic diameter $(\mathrm{cm})$ & $5.1 \pm 1.1$ & $5 \pm 0.95$ & $5.1 \pm 0.87$ & $5.4 \pm 0.88$ & .1 \\
\hline LV end-systolic diameter $(\mathrm{cm})$ & $3.7 \pm 1.4$ & $3.3 \pm 0.92$ & $3.4 \pm 0.88$ & $3.8 \pm 1.0$ & .09 \\
\hline Left atrial diameter $(\mathrm{cm})$ & $5 \pm 0.77$ & $5 \pm 0.78$ & $5.3 \pm 1.0$ & $5.5 \pm 0.88$ & .0005 \\
\hline Fractional shortening & $0.30 \pm 0.14$ & $0.33 \pm 11$ & $0.35 \pm 0.11$ & $0.30 \pm 0.11$ & .008 \\
\hline Ejection fraction (\%) & $54 \pm 22$ & $59 \pm 17$ & $62 \pm 15$ & $56 \pm 16$ & .01 \\
\hline Estimated wall stress & $0.51 \pm 0.17$ & $0.51 \pm 0.21$ & $0.47 \pm 0.13$ & $0.45 \pm 0.13$ & .03 \\
\hline \multicolumn{6}{|l|}{ Noncardiac comorbidity } \\
\hline $\mathrm{BUN}\left(\mathrm{mg} \cdot \mathrm{dL}^{-1}\right)$ & $23 \pm 13$ & $22 \pm 9$ & $21 \pm 8$ & $21 \pm 8$ & $>.9$ \\
\hline Bilirubin $\left(\mathrm{mg} \cdot \mathrm{dL}^{-1}\right) \ddagger$ & $0.5,0.8,1.4$ & $0.5,0.8,1.3$ & $0.5,0.8,1.4$ & $0.45,1.0,1.5$ & .6 \\
\hline Hematocrit (\%) & $38 \pm 6$ & $38 \pm 6$ & $38 \pm 5$ & $38 \pm 5$ & .8 \\
\hline \multicolumn{6}{|l|}{ Intraoperative support } \\
\hline Aortic clamp time (min) & $81 \pm 31$ & $92 \pm 34$ & $90 \pm 32$ & $89 \pm 25$ & .006 \\
\hline CPB time (min) & $112 \pm 40$ & $115 \pm 40$ & $113 \pm 37$ & $116 \pm 33$ & .5 \\
\hline
\end{tabular}

$A F$, Atrial fibrillation; $L V$, left ventricular; $B U N$, blood urea nitrogen; $C P B$, cardiopulmonary bypass. *Mean $\pm S D$ unless otherwise noted. $†$ Wilcoxon rank-sum nonparametric test. $¥$ Median, 15 th, and 85 th percentiles. 


\begin{tabular}{|c|c|c|}
\hline Factor & Estimate $\pm \mathrm{SE}$ & $P$ value \\
\hline \multicolumn{3}{|l|}{ Lesion set 2 vs lesion set 1} \\
\hline Date of operation & $-32 \pm 13$ & .01 \\
\hline Date of operation* & $390 \pm 155$ & .01 \\
\hline Fewer with RCA system disease & $-0.66 \pm 0.31$ & .03 \\
\hline Higher ejection fractiont & $1.6 \pm 0.48$ & .0006 \\
\hline Longer aortic clamp time & $0.015 \pm 0.005$ & .002 \\
\hline More with a mitral procedure & $1.2 \pm 0.33$ & .0002 \\
\hline \multicolumn{3}{|l|}{ Lesion set 3 vs lesion set 1} \\
\hline Higher ejection fractiont & $1.9 \pm 0.57$ & .0009 \\
\hline Fewer with paroxysmal AF & $-1.3 \pm 0.37$ & .0007 \\
\hline Fewer with RCA system disease & $-0.89 \pm 0.33$ & .006 \\
\hline Longer aortic clamp time & $0.016 \pm 0.0053$ & .004 \\
\hline Longer duration of AF‡ & $0.31 \pm 0.11$ & .006 \\
\hline Fewer with heart failure & $-0.93 \pm 0.33$ & .004 \\
\hline More with a mitral procedure & $1.5 \pm 0.37$ & $<.0001$ \\
\hline Fewer with diabetes & $-1.2 \pm 0.51$ & .02 \\
\hline \multicolumn{3}{|l|}{ Lesion set 4 vs lesion set 1} \\
\hline Date of operation & $29 \pm 10$ & .002 \\
\hline Date of operation* & $-333 \pm 116$ & .004 \\
\hline Fewer with paroxysmal AF & $-1.4 \pm 0.42$ & .0005 \\
\hline Higher ejection fractiont & $1.5 \pm 0.50$ & .003 \\
\hline Fewer with RCA system disease & $-1.5 \pm 0.36$ & $<.0001$ \\
\hline Smaller septum§ & $2.9 \pm 1.0$ & .004 \\
\hline Longer aortic clamp time & $0.020 \pm 0.0057$ & .0003 \\
\hline Fewer with aortic valve stenosis & $-1.3 \pm 0.45$ & .003 \\
\hline More with a mitral procedure & $1.2 \pm 0.39$ & .003 \\
\hline
\end{tabular}

$R C A$, Right coronary artery; $A F$, atrial fibrillation. *Ln(interval from date of operation to $1 / 1 / 1991)$, logarithmic transformation. $\dagger \operatorname{Ln}($ ejection fraction), logarithmic transformation. $\$$ Ln(duration of $A F)$, logarithmic transformation. §Ln(relative wall thickness +5 ), logarithmic transformation. 


\begin{tabular}{|c|c|c|c|c|}
\hline \multirow[b]{2}{*}{ Characteristic } & \multicolumn{3}{|c|}{ Lesion set } & \multirow[b]{2}{*}{$P$ value } \\
\hline & $\begin{array}{c}\text { 1, n }=101(38 \%) \\
\text { No. }(\%)\end{array}$ & $\begin{array}{c}2, n=45(17 \%) \\
\text { No. }(\%)\end{array}$ & $\begin{array}{c}3 / 4, n=121(45 \%) \\
\text { No. }(\%)\end{array}$ & \\
\hline \multicolumn{5}{|l|}{ Demographic } \\
\hline Age $(y)$, mean $\pm S D$ & $71 \pm 11$ & $70 \pm 9$ & $69 \pm 10$ & .3 \\
\hline \multicolumn{5}{|l|}{ Cardiac comorbidity } \\
\hline Left main disease* & $14(15)$ & $5(11)$ & $4(3)$ & .01 \\
\hline LAD disease ${ }^{*}$ & $48(51)$ & $16(37)$ & $28(24)$ & .0002 \\
\hline Circumflex disease ${ }^{*}$ & $39(41)$ & $14(32)$ & $26(22)$ & .01 \\
\hline Right coronary disease* & $45(48)$ & $15(35)$ & $26(22)$ & .0004 \\
\hline Previous myocardial infarction & $46(46)$ & $11(24)$ & $24(20)$ & .0001 \\
\hline \multicolumn{5}{|l|}{ Mitral valve disease cause } \\
\hline Rheumatic & $13(13)$ & $12(27)$ & $25(21)$ & .1 \\
\hline Degenerative & $24(24)$ & $22(49)$ & $66(55)$ & $<.0001$ \\
\hline Mitral valve regurgitation grade & & & & .004 \\
\hline $0+$ & $21(21)$ & $9(20)$ & $11(9)$ & \\
\hline $1+$ & $21(21)$ & $6(13)$ & $12(10)$ & \\
\hline $2+$ & $21(21)$ & $5(11)$ & $16(13)$ & \\
\hline $3+$ & $15(15)$ & $8(18)$ & $27(22)$ & \\
\hline $4+$ & $23(23)$ & $17(38)$ & $55(45)$ & \\
\hline Ejection fraction $(\%)$, mean $\pm S D$ & $50 \pm 20$ & $58 \pm 14$ & $62 \pm 16$ & .002 \\
\hline Left atrial diameter $(\mathrm{cm}) \dagger$ & $4.2,5.2,6.0$ & $4.4,5.0,5.9$ & $4.7,5.5,6.6$ & .01 \\
\hline$>6 \mathrm{~cm}$ & $13(16)$ & $4(12)$ & $31(30)$ & .03 \\
\hline Fractional shortening $†$ & $0.12,0.26,0.42$ & $0.22,0.30,0.45$ & $0.23,0.34,0.47$ & .001 \\
\hline \multicolumn{5}{|l|}{ Procedure } \\
\hline Mitral valve repair & $26(26)$ & $15(33)$ & $64(53)$ & .0001 \\
\hline Mitral valve replacement & $22(22)$ & $19(42)$ & $37(31)$ & .04 \\
\hline CABG & $56(55)$ & $20(44)$ & $34(28)$ & .0002 \\
\hline \multicolumn{5}{|l|}{ Lesion } \\
\hline Right atrial & $8(8)$ & $6(13)$ & $96(79)$ & $<.0001$ \\
\hline
\end{tabular}

$L A D$, Left anterior descending coronary artery; $C A B G$, coronary artery bypass grafting. * $>50 \%$. $†$ Median, 15 th, and 85 th percentiles. 
Electronic Appendix 5. Distribution of electrocardiographic records over time

\begin{tabular}{|c|c|c|c|c|c|c|}
\hline Time (mo) & 0 & 1 & 3 & 6 & 9 & 12 \\
\hline \multicolumn{7}{|l|}{ Overall } \\
\hline No. of patients & 513 & 313 & 253 & 195 & 120 & 72 \\
\hline No. of ECGs & 3495 & 1070 & 694 & 401 & 219 & 113 \\
\hline \multicolumn{7}{|l|}{ Lesion set 1} \\
\hline No. of patients & 194 & 115 & 91 & 69 & 47 & 26 \\
\hline No. of ECGs & 1278 & 414 & 270 & 167 & 91 & 46 \\
\hline \multicolumn{7}{|l|}{ Lesion set 2} \\
\hline No. of patients & 96 & 74 & 61 & 49 & 21 & 13 \\
\hline No. of ECGs & 676 & 233 & 150 & 80 & 39 & 15 \\
\hline \multicolumn{7}{|l|}{ Lesion set 3} \\
\hline No. of patients & 96 & 72 & 67 & 51 & 35 & 24 \\
\hline No. of ECGs & 805 & 300 & 207 & 113 & 66 & 39 \\
\hline \multicolumn{7}{|l|}{ Lesion set 4} \\
\hline No. of patients & 87 & 34 & 17 & 14 & 10 & 5 \\
\hline No. of ECGs & 496 & 67 & 30 & 20 & 13 & 6 \\
\hline \multicolumn{7}{|l|}{ Other lesions } \\
\hline No. of patients & 40 & 18 & 17 & 12 & 7 & 4 \\
\hline No. of ECGs & 240 & 56 & 37 & 21 & 10 & 7 \\
\hline
\end{tabular}

ECG, Electrocardiogram. 


\section{Electronic Appendix 6. Variables used in the analyses}

\begin{tabular}{|c|c|}
\hline \multicolumn{2}{|l|}{ Preoperative } \\
\hline Demographic & Age $(\mathrm{y})$, sex, weight $(\mathrm{kg})$, height $(\mathrm{cm})$, body surface area $\left(\mathrm{m}^{2}\right)$, body mass index $\left(\mathrm{kg} \cdot \mathrm{m}^{-2}\right)$ \\
\hline Symptoms & New York Heart Association functional class (I-IV), emergency operation \\
\hline Left ventricular function & $\begin{array}{l}\text { Ejection fraction }(\%) \text {, end-diastolic diameter }(\mathrm{cm}) \text {, end-systolic diameter }(\mathrm{cm}) \text {, fractional } \\
\text { shortening, mass }(\mathrm{g}) \text {, mass index }\left(\mathrm{g} \cdot \mathrm{m}^{-2}\right) \text {, end-diastolic volume }(\mathrm{mL}) \text {, end-systolic } \\
\text { volume }(\mathrm{mL}) \text {, end-diastolic volume index }\left(\mathrm{mL} \cdot \mathrm{m}^{-2}\right) \text {, end-systolic volume index }(\mathrm{mL} \text {. } \\
\left.\mathrm{m}^{-2}\right) \text {, posterior wall thickness }(\mathrm{cm}) \text {, estimated wall stress }\end{array}$ \\
\hline Right ventricular function & Estimated systolic pressure \\
\hline Atrial size & LA diameter $(\mathrm{cm})$, LA volume $(\mathrm{mL}), \mathrm{LA}$ volume index $\left(\mathrm{mL} \cdot \mathrm{m}^{-2}\right)$ \\
\hline Mitral valve pathology & Mitral regurgitation \\
\hline Mitral valve disease cause & Ischemic, rheumatic, degenerative \\
\hline Other valve pathology & Aortic valve regurgitation, tricuspid valve regurgitation \\
\hline Cardiac comorbidity & Complete heart block-pacer, ventricular arrhythmia, number of previous cardiac operations \\
\hline Noncardiac comorbidity & $\begin{array}{l}\text { Insulin-treated diabetes, non-insulin-treated diabetes, treated diabetes, history of } \\
\text { peripheral vascular disease, history of smoking, carotid disease, chronic obstructive } \\
\text { pulmonary disease, hypertension, renal disease, creatinine }\left(\mathrm{mg} \cdot \mathrm{dL}^{-1}\right) \text {, blood urea } \\
\text { nitrogen }\left(\mathrm{mg} \cdot \mathrm{dL}^{-1}\right) \text {, bilirubin }\left(\mathrm{mg} \cdot \mathrm{dL}^{-1}\right) \text {, hematocrit }(\%)\end{array}$ \\
\hline Coronary anatomy & $\begin{array}{l}\text { Maximum \% stenosis in: left main trunk, left anterior descending coronary artery system, } \\
\text { right coronary artery system, left circumflex coronary artery system }\end{array}$ \\
\hline Experience & Date of operation (years since January 1, 2001) \\
\hline Atrial fibrillation types & Permanent, persistent, paroxysmal, duration of atrial fibrillation (mo) \\
\hline Thromboembolic events & Transient ischemic attack, cerebrovascular accident \\
\hline \multicolumn{2}{|l|}{ Intraoperative } \\
\hline Procedure & $\begin{array}{l}\text { Internal thoracic artery graft used, coronary artery bypass grafting, tricuspid valve repair, } \\
\text { MV repair, MV replacement, MV bioprosthetic replacement, aortic valve replacement }\end{array}$ \\
\hline Lesion sets & $\begin{array}{l}\text { Lesion set } 1 \text {, lesion set } 2 \text {, lesion set } 3 \text {, lesion set } 4 \text {, connection to mitral annulus, } \\
\text { connection between inferior pulmonary veins, connection between superior pulmonary } \\
\text { veins, connection to left atrial appendage, right atrial lesion }\end{array}$ \\
\hline Source & Cryothermy \\
\hline Support & Aortic clamp time (min), cardiopulmonary bypass time (min) \\
\hline
\end{tabular}

$L A$, Left atrium; $M V$, mitral valve.

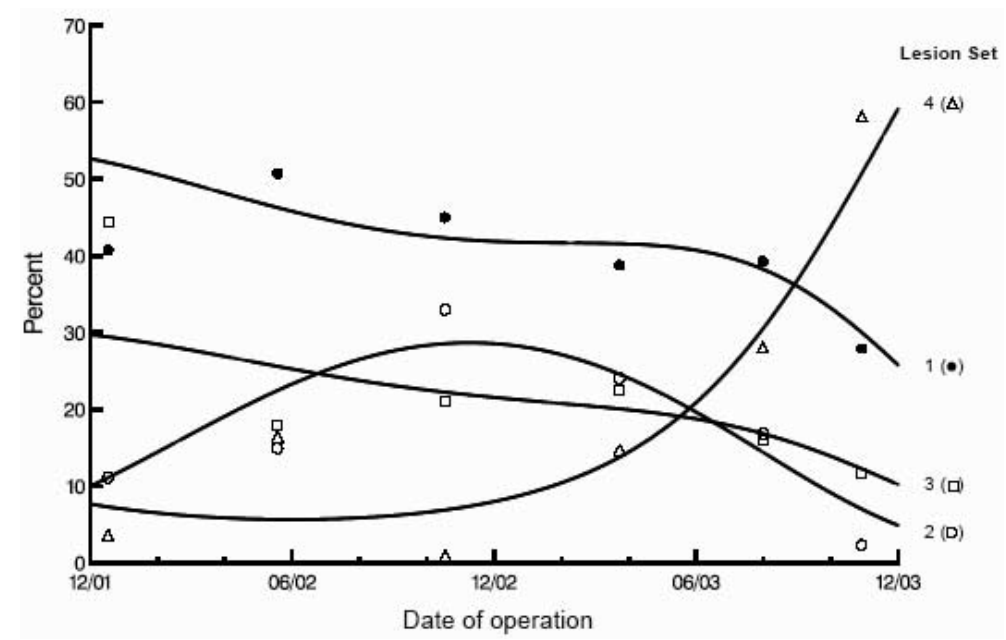

Electronic Appendix Figure E1. Use of various lesion sets (1-4) across the study period. 


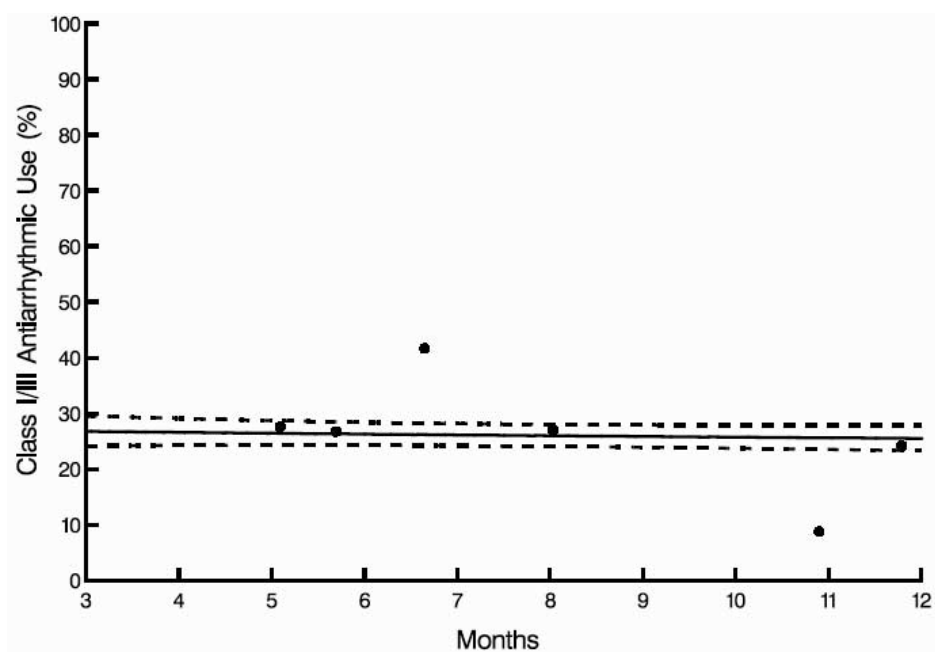

Electronic Appendix Figure E2. Prevalence of class I and III antiarrhythmic agent use after ablation. The horizontal axis begins at 3 months, marking the first systematic follow-up of patients. Filled circles represent observed prevalences, but only approximate the data because of multiple follow-up inquiries per patient. The solid curve represents the prevalence estimate from the logistic mixed model, and dashed lines represent $68 \%$ confidence limits.

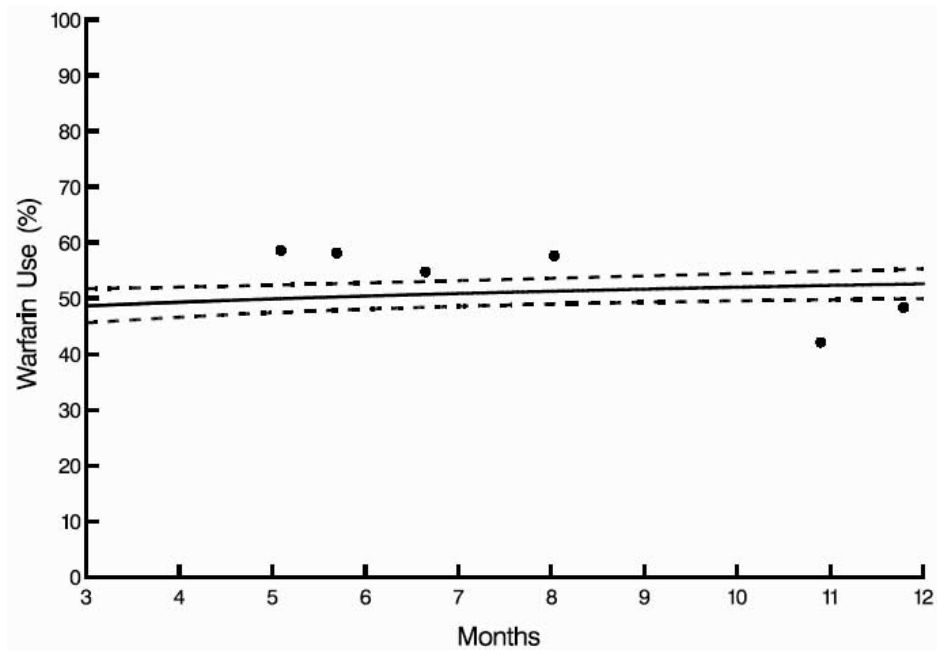

Electronic Appendix Figure E3. Prevalence of warfarin use after ablation. Format is as for Electronic Appendix Figure E2. 


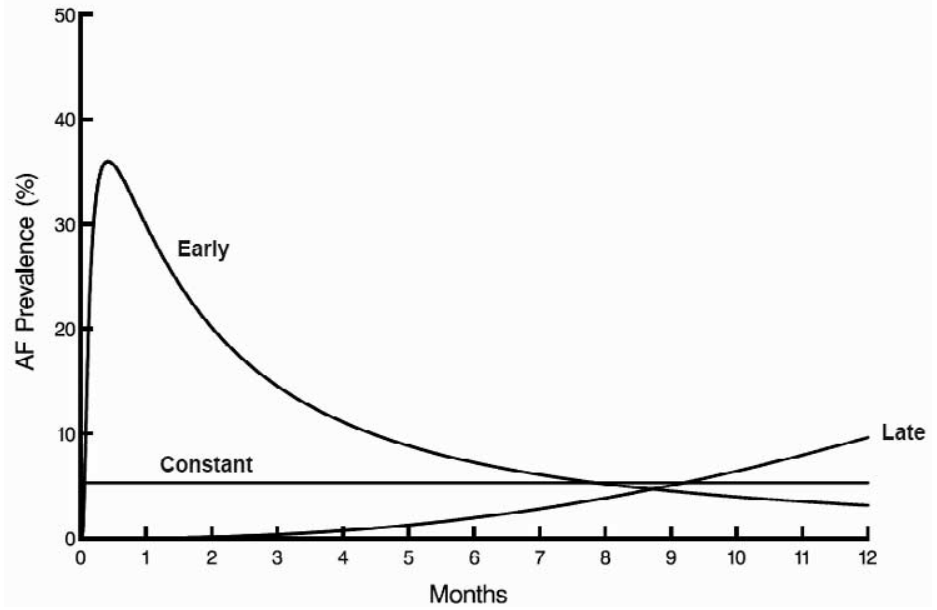

Electronic Appendix Figure E4. Decomposition of temporal pattern of atrial fibrillation (AF) after ablation, based on postoperative electrocardiograms, demonstrating 3 phases of prevalence: an early peaking phase, a constant phase, and a late rising phase.

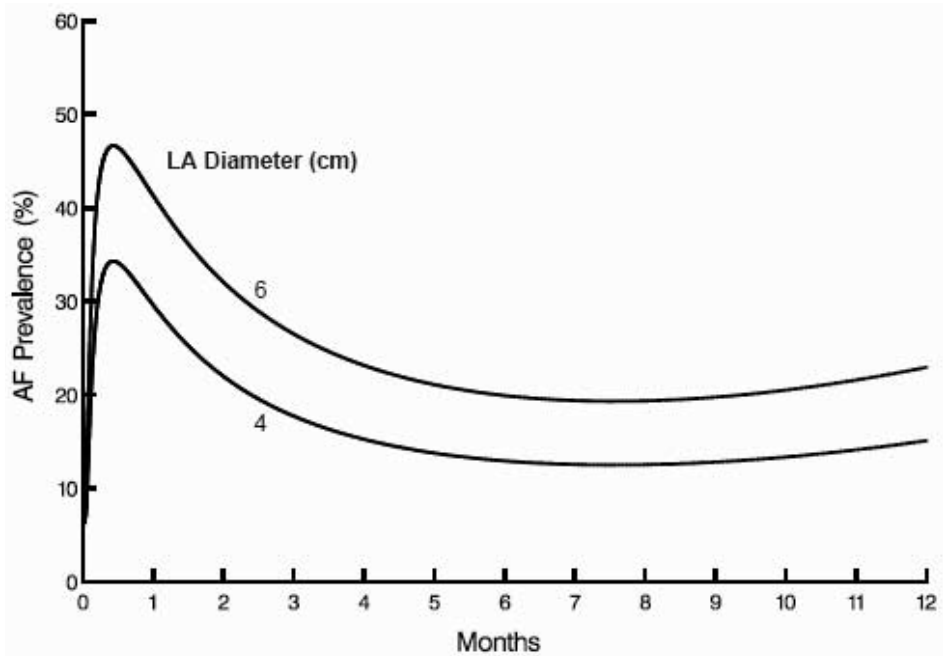

Electronic Appendix Figure E5. Nomogram from the multivariable equation (Table 2) demonstrating the effect of 2 left atrial diameters. 


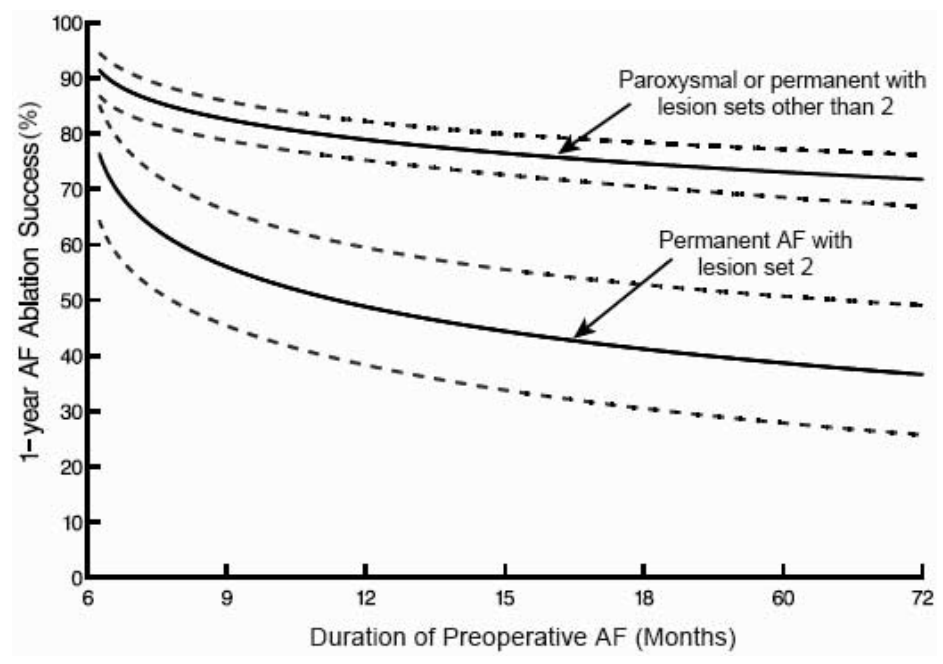

Electronic Appendix Figure E6. Effect of (1) lesion set, (2) type of atrial fibrillation (AF), and (3) duration of AF (along horizontal axis) on estimated 1-year freedom from ablation failure (vertical axis) based on multivariable analysis (see Table 3). Dashed lines enclose 68\% confidence limits. 